\title{
El Corpus Académico y Profesional del Español PUCV-2006: semejanzas y diferencias entre los géneros académicos y profesionales*
}

\author{
The Academic and Professional Corpus of PUCV-2006 Spanish: \\ similarities and differences of the identified academic and professional genres
}

\author{
Giovanni Parodi \\ Pontificia Universidad Católica de Valparaíso, Valparaíso, Chile, \\ e-mail: gparodi@ucv.cl
}

Los elusivos conceptos subyacentes al término género ofrecen diferentes concepciones alternativas. Ello puede confundir al novato, pero también al experto. En este artículo se entrega una discusión acerca de las concepciones de género discursivo. También se propone una perspectiva con especial énfasis en una concepción cognitiva y con hallazgos empíricos. La investigación propiamente tal se basa en la descripción del más amplio corpus digital disponible en línea (59 millones de palabras) de textos especializados en español en cuatro disciplinas: Psicología, Trabajo Social, Química Industrial e Ingeniería en Construcción. El corpus fue recolectado en una universidad chilena y en los correspondientes entornos profesionales. Los datos revelan que el acceso al conocimiento disciplinar se construye a través, por un lado, de un repertorio variado de nueve géneros académicos escritos y, por otro, de un conjunto más amplio y heterogéneo de veintiocho géneros profesionales. Se detectan interesantes variaciones a través de las cuatro disciplinas. Implicaciones psicolingüísticas y educacionales se entregan en relación a la adquisición de conocimiento, los géneros discursivos y la comprensión lingüística.

Palabras clave: género académico, género profesional, corpus, cognitivismo.

The elusive concepts underlying the term genre offer different alternative conceptions. This may confuse the novice, but also the expert. This article addressed a discussion on the contemporary conceptions of discourse genre. Also, a particular cognitive perspective was focused, but with special emphasis on findings from empirical data. The research was based on the description of the largest available on-line corpus (59 million words) of written specialized Spanish texts on four disciplines: Psychology, Social Work, Industrial Chemistry, and Construction Engineering. The corpus was collected in one Chilean university and in the corresponding professional backgrounds, and it showed that the access to disciplinary knowledge is build upon, on the one hand, a varying repertoire of nine written academic genres, and on the other, a richer group of twenty eight professional genres. Interesting variations between the four disciplines under study were identified. Psycholinguistic and educational implications were advanced in relation to knowledge acquisition, discourse genres and reading comprehension.

Key words: academic genre, professional genre, corpus, cognitivism.

\footnotetext{
* Proyecto Fondecyt $\mathrm{N}^{\circ} 1060440$ (Conicyt).
} 


\section{INTRODUCCIÓN}

Existe suficiente información disponible que muestra los problemas de comprensión de diversos lectores al enfrentar géneros especializados escritos tanto académicos como profesionales (Parodi 2005, 2007a, b; Arnoux; Nogueira y Silvestri 2006; Peronard 2007 e Ibáñez 2007). Situación similar ocurre en el ámbito de la escritura académica y profesional (Parodi 2003; Marinkovich 2001-2003 y Carlino, 2005). Estos géneros encierran una serie de características no suficientemente descritas, desde ámbitos disciplinares particulares, y ello hace que los lectores y escritores que los enfrentan tengan problemas para su cabal comprensión profunda. En parte, todo ello genera actitudes epistémicas negativas hacia los textos especializados, ya que se tienden a visualizar como de difícil accesibilidad. Al mismo tiempo, y en virtud de lo anterior, la incorporación al grupo especializado se torna más lenta y compleja.

Muchos de los estudios realizados no permiten distinguir con absoluta claridad los géneros discursivos asociados, por un lado, al ámbito académico y, por otro, al profesional. Un número importante de investigaciones se ha focalizado preferentemente en disciplinas como la medicina, las leyes, los negocios, la historia y en el terreno de las organizaciones gubernamentales (Trosborg 2000; Gallardo 2005; Alcaraz Varó, Mateo y Yus 2007; Ciapuscio 2007; Facchinetti 2007; Mahlberg y Teubert 2007; Candlin 2002; Devitt 2004 y Oteíza 2006), no existiendo estudios empíricos robustos en otras áreas del saber, salvo escasas excepciones (entre otras, Bruce 2008; Biber, Connor y Upton 2007; Wignell 2007; Connor y Upton 2004; Curado, Edwards y Rico 2007; Flowerdew 2002; Swales 2004 y Vine 2004). No se cuenta con antecedentes de tipo contrastivo entre un grupo de carreras universitarias y su correspondiente ámbito profesional laboral, o sea, desde la perspectiva amplia de la retórica contrastiva. De modo más específico, los trabajos que existen en español sobre estas temáticas son de reciente data y centrados en el discurso especializado o el discurso académico (entre otros, Cubo de Severino 2005; Castel, Aruani y Severino 2004; Harvey 2005; Ciapuscio 2003; Torner y Battaner 2005; Castelló 2007; Parodi 2004, 2005, 2007a, b, 2008a; Montolío 2002 y Núñez, Muñoz y Mihovilovic 2006). A partir de este marco, la investigación de que damos cuenta se encuadra dentro de los estudios basados en grandes corpus de textos. Ello porque pretendemos avanzar hacia una descripción más ecológica y representativa de la variación a través de las disciplinas y a través de los géneros. De este modo, en este artículo aporto algunos antecedentes acerca de un proyecto en marcha (FONDECYT 1060440) en la Pontificia Universidad Católica de Valparaíso, Chile, centrado en la recolección, construcción y descripción de un corpus de discurso escrito en el ámbito académico y en el profesional en cuatro áreas disciplinares: Química Industrial, Ingeniería en Construcción, Trabajo Social y Psicología. En la primera parte del trabajo se entregan algunos núcleos conceptuales a modo de referentes teóricos que enmarcan la investigación; en especial, se precisan ciertos fundamentos acerca de los géneros discursivos. En la segunda parte se describe el corpus y comparan los géneros detectados en el nivel académico y en el profesional. Concluyo el trabajo con algunas proyecciones, reflexiones y comentarios. 


\section{Algunos núCleos Conceptuales}

\subsection{GENEROS ACADEMICOS Y GENEROS PROFESIONALES}

Como se sabe, el lenguaje escrito es el medio preferente mediante el cual se crea, fija y transmite el conocimiento disciplinar; específicamente, a través de aquellos géneros prototípicos que andamian la construcción inicial de saberes especializados y que, gradualmente, van cimentando la integración a una comunidad discursiva particular. Desde este contexto, los géneros académicos y profesionales se operacionalizan a través de un conjunto de textos que se organizan a través de un continuum en el que se van concatenando desde los textos escolares generales hacia los académicos universitarios y los profesionales. Ahora bien, centrados en el eje de nuestra investigación, nos competen dos ámbitos específicos. Entre ellos esperamos encontrar ciertos géneros que se entrecrucen y que constituyan anclajes epistémicos a modo de vasos comunicantes entre un ámbito académico y su correlato profesional. Estos pasajes entre el mundo universitario y el mundo laboral constituirían nichos en que el conocimiento avanza más fluidamente, de modo que se espera que el sujeto lector se apoye en un género ya conocido para proyectarse hacia nuevos escenarios discursivos. La Figura 1 muestra estas interacciones y solapamientos, a la vez que da cuenta de la posible transversalidad de ciertos géneros a través de las disciplinas. Por supuesto que estos marcos teóricos serán contrastados con la investigación empírica posterior.

Figura 1

Las disciplinas y los géneros académicos y profesionales

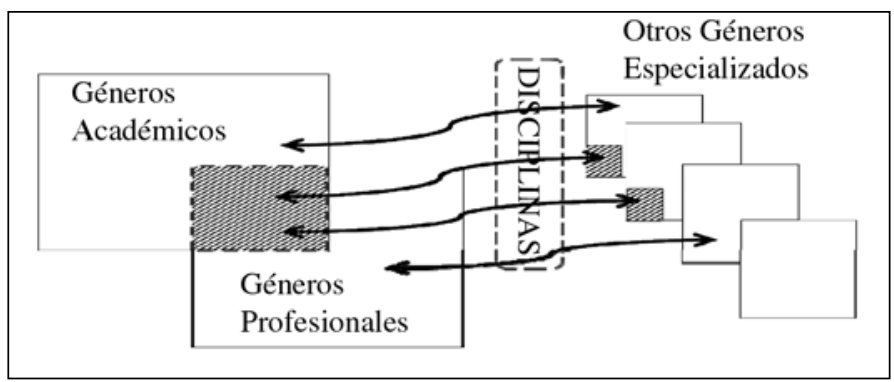

Hasta hace muy poco tiempo, o incluso todavía para algunos, la concepción del discurso académico tendía a visualizarlo como un conjunto de géneros muy unificado, en particular desde los dominios de la enseñanza-aprendizaje de lenguas (Swales 1990, 1998, 2004; Hyland 1998, 2000). Nuestro punto de vista en este aspecto, por una parte, apunta a que algunos de estos géneros discursivos pueden variar grandemente a través de las disciplinas e incluso dentro de una misma disciplina (Bhatia 1993, 2004; Parodi 2005, 2007a, b, 2008b; Ibáñez 2008 y Parodi e Ibáñez 2008). Por otra, la investigación empírica también ha demostrado que otros géneros muy específicos pueden mantenerse relativamente homogéneos a través de varias disciplinas científicas (Venegas 2006; Parodi 2007a). Tal como sostiene acertadamente Bhatia (2004), los géneros cruzan transversalmente a las disciplinas, aunque es factible que, 
por supuesto, exista heterogeneidad al interior de un mismo género así como entre las disciplinas. La idea de conjuntos de géneros y sistemas de géneros (Bazerman 1994), colonias de géneros (Bhatia 2004) o macrogéneros (Martin y Rose 2008) pretende -en parte- dar cuenta de ello. De este modo, los géneros discursivos pueden cruzar transversalmente tanto al discurso académico como el discurso profesional desde una o varias disciplinas.

Volviendo a la Figura 1, las flechas bidireccionales muestran justamente estos posibles puntos de intersección entre géneros académicos, profesionales y otros géneros especializados, mientras todos ellos transitan a través de diversas disciplinas, tanto a partir de las áreas de comunalidad como las altamente específicas al interior de una disciplina o entre géneros mismos. En efecto, el área achurada de intersección pretende dar cuenta de ello. Como se comprende, se abre así un abanico de posibilidades de investigación. Entre otros, la determinación de estos escenarios discursivos presenta interesantes implicaciones científicas, tanto en un terreno teórico como aplicado o directamente pedagógico.

Algunos de estos géneros serán prototípicos de un solo ámbito, ya sea el académico o el profesional; o de una sola disciplina. Otros estarán presentes en varios contextos y adquirirán posiblemente formas y funciones diversas. De hecho, las líneas punteadas de la intersección académico-profesional destacan el carácter provisional de los géneros allí encontrados. Es una frontera difusa que puede llegar a ser eventualmente traspasada por géneros en transición.

\subsection{HACIA UNA CONCEPCION INTEGRAL DE LOS GENEROS}

En un intento por conceptualizar el complejo proceso de construcción y aprendizaje a partir de las prácticas discursivas académicas y profesionales, visualizo dichos procesos como un circuito, dado el carácter altamente sinérgico en que las diversas instancias comunicativas aportan y reaportan a la construcción social de conocimientos especializados. En este circuito intento capturar un conjunto de variables relevantes al proceso de construcción y apropiación de géneros disciplinares, así como destacar las conexiones direccionales y bidireccionales en que concibo el flujo de conocimientos y actividades cognitivas situadas tanto individuales como en vinculación con la comunidad. La Figura 2 grafica este circuito que se enmarca en el contexto social y cultural.

Como se aprecia, las dimensiones implicadas en los géneros discursivos ponen en juego unas acciones y relaciones vinculantes que dan paso a la construcción de conocimientos especializados. En este circuito de construcción de los géneros especializados, un sujeto que ingresa a una comunidad discursiva en el nivel universitario debe acceder a un conocimiento disciplinar, preferentemente, a través de la lectura de los textos de su currículo. Todo ello en el contexto de una serie de actividades formales como son las asignaturas de su plan de estudios y las exigencias evaluativas y las interacciones con sus profesores y sus compañeros de grupo. Este sujeto está así sumergido en un conjunto de géneros orales y escritos que andamian su construcción de conocimientos especializados.

En el contexto de este circuito de construcción y reconstrucción de prácticas discursivas, la comprensión de los materiales escritos se complementa gradualmente con la práctica de la escritura de géneros especializados. Las relaciones sinérgicas 
Figura 2

Circuito de la construcción de géneros académicos y profesionales

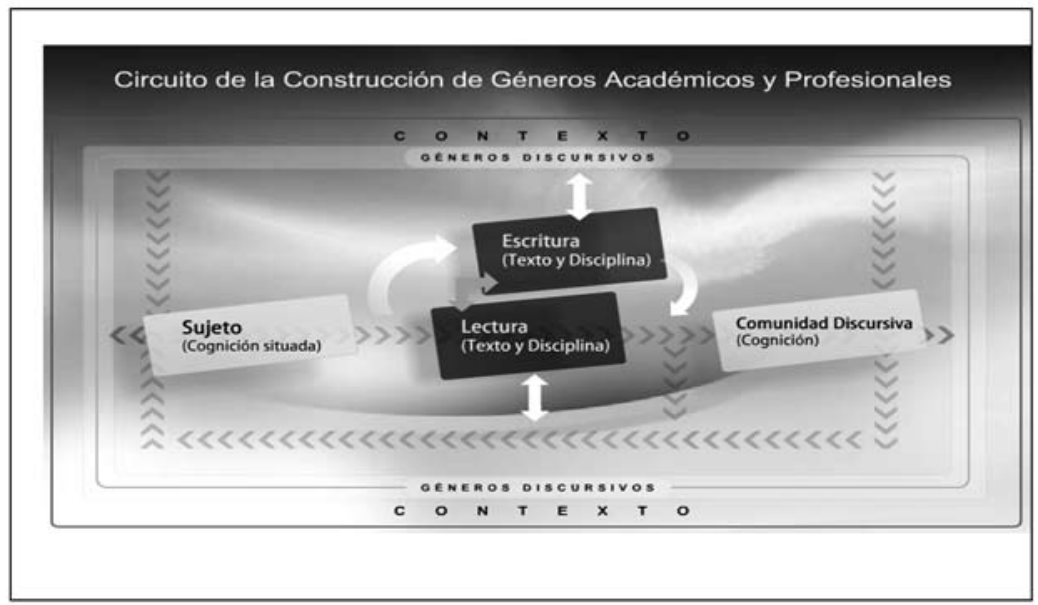

entre ambas prácticas de lectura y de escritura especializadas van transformando el conocimiento disciplinar y el sujeto va adquiriendo progresivamente un dominio de los géneros disciplinares, por medio de un proceso de índole ontogenética. Algunos de estos géneros solo serán leídos como acceso a conocimientos específicos, otros constituirán tareas de escritura con el fin de comunicar, por este medio, informaciones específicas. Algunos de estos géneros académicos deberán ser leídos inicialmente y, posteriormente, ejercerán su máximo cometido comunicativo, cuando el aprendiz sea capaz de escribirlos adecuadamente y cumplan funciones comunicativas relevantes en las prácticas sociales y académicas. Como se desprende, llegado el momento en que el sujeto escritor sea competente en aquellos géneros especializados altamente prototípicos de la disciplina, habrá demostrado su incorporación efectiva a su comunidad, lo que le permitirá comunicar significados especializados. De este modo, la lectura es un paso fundamental en el acceso al conocimiento y la estructura discursiva del material escrito, pero solo la producción efectiva de los géneros requeridos revela el máximo nivel de competencia discursiva de un sujeto.

\subsubsection{Los géneros como constructos cognitivos}

En mi opinión, una concepción multidimensional de los géneros debe visualizar los diferentes ejes que lo componen. Al menos, debe determinar dimensiones básicas que andamien la concepción compleja a la cual adherimos. La dimensión cognitiva, la dimensión social y la dimensión lingüística se proponen como fundamentales y dan así forma a los géneros discursivos. Sin negar estos tres ejes propuestos y las diversas interacciones implicadas en este concepto de género, deseo -en este momento- destacar una concepción de los géneros discursivos, preferentemente, como constructos cognitivos. En mi opinión, esta dimensión que resaltamos no ha sido suficientemente considerada y se ha tendido a una excesiva mirada semiótica externalista del constructo género (Halliday 1978; Kress y Threadgold 1988; Martin 1992 y Martin y Rose, 2008). 
En todo caso, de ningún modo busco atomizar la exquisita riqueza que enmarca a los géneros, sino más bien introducir una dimensión que estimo ha sido, intencional o ingenuamente, olvidada o descuidada, y que juzgo central para una comprensión cabal del objeto en cuestión (una discusión más detallada respecto del continuиm internalismo-externalismo se encuentra en Parodi, 2008a).

Ahora bien, es muy cierto que un sujeto va construyendo sus conocimientos en interacción con otros sujetos y en contextos que demandan instrumentos discursivos diversos, pero no es menos cierto que ese conocimiento, elaborado a través de procesos ontogenéticos, se almacena en la memoria de los lectores/escritores y hablantes/ oyentes en un formato representacional complejo, aún no totalmente determinado. $\mathrm{Al}$ respecto, dos conceptos singulares resultan relevantes para la dimensión cognitiva de los géneros. Durante los últimos años el llamado modelo de situación (van Dijk y Kintsch 1983) ha adquirido relevancia como una instancia de alto nivel representacional de conocimiento en el procesamiento del discurso. Es posible sostener que tal nivel de representación cognitivo podría dar cuenta también del conocimiento de los géneros, dado que los géneros existen porque el lector/oyente experto debería contar con una representación mental de la situación social en que éstos se producen y emplean. Complementariamente, el concepto de modelo de contexto, acuñado más recientemente por van Dijk (van Dijk 1999, 2006, 2008), también da cuenta del tipo de conocimiento al que aludimos y resalta el carácter cognitivo del constructo contexto en el procesamiento del discurso. Desde estos dos modelos dan cuenta de conocimientos de diversos tipos, algunos más procedurales, otros más declarativos. Ambos modelos se ofrecen como un camino para la mejor comprensión y explicación del modo de operar cognitivamente de los géneros discursivos, pero se requiere investigación empírica que avale esta propuesta. Por razones de espacio, no me detengo aquí en explicaciones pormenorizadas de uno u otro modelo.

Esta concepción da cuenta de una visión más amplia y refleja la multidimensionalidad del concepto de género. Se asume así que los géneros son más que meras constantes sociales, a modo de patrones de comportamiento e interacción (definidos únicamente por variables del contexto social: el lugar, los participantes, etc.). Con ello intento aportar una perspectiva más abarcadora e integral y superar, en lo posible, los reduccionismos implicados en visiones extremadamente retóricas o contextualistas (Parodi 2008a). Del mismo modo, como se indicó más arriba, destaco la dimensión cognitiva de los géneros porque con ello busco apuntar el rol central del ser humano como sujeto hablante/escribiente y oyente/lector dentro de un proceso de comunicación muy dinámico y participativo. Este sujeto es quien -en definitiva- construye en su mente los géneros discursivos como instrumentos comunicativos, a partir de contextos y situaciones sociales específicas y -por supuesto- en interacción con otros sujetos. Así, el conocimiento de los géneros, construido individual y socialmente, se almacena a modo de representaciones cognitivas y, desde esta óptica, ellos serán activados y se realizarán en constructos textuales específicos, dentro de contextos sociales y culturales, según sea el caso.

Como se ha venido argumentando, defiendo un concepto integral de género y no distingo géneros sociales y géneros cognitivos (Bruce 2008) o variantes más sociales y otras más lingüísticas o cognitivas (van Dijk 2008). Si a lo que se apunta en la mirada de Bruce o van Dijk es a distinguir planos o dimensiones dentro de una concepción integral, quiere decir que hablamos de lo mismo. Si lo que se rescata en 
uno u otro de estos autores son géneros diferentes en planos diferentes, ciertamente no coincido con tal propuesta.

Entonces, la visión psicosocio-discursiva del lenguaje que sustento aborda, al menos, vínculos entre procesamientos cognitivos, representaciones mentales, enunciados contextualizados, interacciones sociales, tipos de aprendizajes y contextos culturales. Como es tradicional, mi mirada se posiciona desde una concepción integral del lenguaje y del ser humano, y desde el desarrollo de competencias de discurso en entornos educativos diversos; así, defendemos una opción original de corte socioconstructivista y deliberadamente cognitivista (Peronard y Gómez Macker 1985; Peronard 2007 y Parodi 2003, 2005, 2007a, 2008a).

\subsection{GENERO: HACIA UNA DEFINICION INTEGRAL}

Sin lugar a dudas proponer una definición concisa de género es asunto complejo. Existe, de hecho, una amplia variedad disponible. Desde múltiples esferas se han aproximado al constructo, más teóricamente, más instruccionalmente, más retóricamente, más gramaticalmente. Sin embargo, se tiende a enfatizar excesivamente un componente más que otro o a focalizar una dimensión en desmedro de otras, dejando, en unos casos, la definición un tanto desbalanceada o, en otros, peligrosamente empobrecida. Por un lado, ello constituye justamente una cuestión de opciones y orientaciones teóricas y metodológicas; por otro, apunta a que en una sola y breve definición no resulta sencillo dar cuenta de la riqueza del concepto o de la amplitud de la definición misma que se intenta proponer. Sea que se defienda una opción, entre otras, desde la nueva retórica (Freedman y Medway 1994; Bazerman 1994, 2008), desde la lingüística aplicada (Swales 1990, 2004; Bhatia 1993, 2004), desde la perspectiva semiodiscursiva (Charaudeau 2004), desde la Escuela de Sydney (Halliday y Hasan 1989; Martin 1992 y Martin y Rose 2008), desde la perspectiva comunicativa alemana (Heinemann 2000; Heinemann y Viehweger, 1991), o desde el análisis del discurso (van Dijk 1997, 2002), la cuestión -en mi opinión- es ser capaz de mirar el fenómeno integralmente.

En mi opinión, el género constituye una constelación de potencialidades de convenciones de tipo discursivo, sustentada por los conocimientos previos de los hablantes/escritores y oyentes/lectores (almacenados en la memoria de cada sujeto), a partir de constricciones y parámetros contextuales, sociales y cognitivos. Esta potencialidad se operacionaliza en conjuntos de selecciones convencionalizadas, las que presentan determinadas regularidades sincrónicamente identificables, pero que también son factibles de ser observadas a modo de variaciones diacrónicas, pues no son entidades de modo estático sino altamente dinámicas. En su manifestación concreta, los géneros son variedades de una lengua que operan a través de conjuntos de rasgos lingüístico-textuales coocurrentes sistemáticamente a través de las tramas de un texto, y que se circunscriben lingüísticamente en virtud de propósitos, destinatarios, contextos de uso, etc. Estos conjuntos de rasgos lexicogramaticales emergen desde corpus representativos de instanciaciones en textos concretos, a partir de los cuales se proyectan regularidades prototípicas que caracterizan a un género determinado en su componente lingüístico (Parodi 2005; Biber, Connor y Upton 2007).

Desde esta perspectiva, los géneros, a modo de estructuras de conocimiento cognitivo, almacenadas como representaciones mentales dinámicas, constituyen un conocimiento de convenciones adquiridas interactivamente por un sujeto en interacción 
con otros. Estos conocimientos convencionalizados, cognitivamente construidos a partir de contextos culturales, orientan los procesos discursivos que los sujetos participantes ponen en práctica en el contrato social. Para que ello ocurra, desde una perspectiva de sujeto experto, requisito sine qua non, es la participación de sujetos conscientes de su rol activo en la interacción comunicativa y de la búsqueda del cumplimiento de los propósitos que persiguen. Ellos deben planificar, monitorear y revisar su participación, con el fin de regular así el cumplimiento del acto comunicativo. El contexto y los roles sociales modelan e imponen restricciones sobre el género; no obstante ello, un sujeto en su madurez discursiva (producto de procesos recursivos ontogenéticos) y en conocimiento de las posibilidades y recursos puede elegir alternativas discursivas, realizar ajustes, proponer cambios y variar el propósito, el foco, etc. Sin duda, es factible que con ello el género varíe y se constituya en otro, pero esa es prerrogativa de los participantes en el acto discursivo. En suma, el sujeto experto en el manejo discursivo no está constreñido por el contexto, sino que puede y debe decidir libremente ajustarse al mismo y actuar en el marco en cuestión. Así, un sujeto puede violar conscientemente alguna de las convenciones de determinado género, pero ciertamente serán sus interlocutores quienes evaluarán la pertinencia de tal posible transgresión.

\section{LA INVESTIGACIÓN: PROCEDIMIENTOS, PASOS METODOLÓGICOS Y CORPUS}

\subsection{PROCEDIMIENTOS Y PASOS METODOLOGICOS}

Tal como se anticipó en la Introducción, en este proyecto buscamos recolectar cerca del $100 \%$ del material escrito que se consulta y se lee durante el total de años del currículo de cada una de estas cuatro carreras universitarias: Psicología, Trabajo Social, Ingeniería en Construcción y Química Industrial. Paralelamente, también recogeremos los textos que circulan y leen los profesionales egresados de estas carreras y que se desempeñan en ámbitos propios a los de su formación de origen.

Cabe destacar que en esta investigación se persiguen principios metodológicos de carácter ecológico y de muestra no intencionada en un sentido estricto. Ello quiere decir que pretendemos acercarnos al universo de textos que circulan en las cuatro áreas disciplinares universitarias; de este modo, el corpus académico no contempla textos ejemplares, muestras aleatorias o materiales mutilados. Así, la investigación adquiere un importante carácter naturalístico, dado que no hemos intervenido ni introducido variables de ningún tipo en la recolección del material mismo (salvo, como se dijo, las de ámbito y nivel). No obstante lo anterior, por supuesto que sí existe un foco en ciertas áreas en la recolección del corpus, a saber, la de las CS\&H y de las CB\&I.

Ahora bien, la metodología más específica de esta investigación se divide en diferentes etapas según el estadio y foco de la misma. Revisamos brevemente los pasos seguidos para uno y otro corpus.

\subsubsection{Recolección del Corpus Académico}

Con el fin de conformar el corpus del nivel académico y construir dicha base de datos electrónica se procedió a través de una serie de pasos. En la Tabla 1 se resumen los nueve pasos ejecutados. 
Tabla 1

Formato empleado para la recolección y procesamiento Corpus Académico

Nueve pasos seguidos para recolectar el Corpus Académico PUCV-2006

Paso 1: Construcción de una base de datos con la información completa de los currículos de las cuatro carreras universitarias (incluyendo los programas de cada asignatura)

Paso 2: Construcción de una base de datos con todas las referencias bibliográficas obligatorias y de consultas, incluidas en los programas de estudio

Paso 3: Preparación de una encuesta para todos los profesores de cada uno de los cuatro programas, la cual incluyó una solicitud de materiales complementarios no incluidos en los programas de asignaturas

Paso 4: Recolección de material complementario a cada asignatura, que los profesores entregan a través de guías, archivos digitales y material fotocopiado

Paso 5: Búsqueda en Internet con el fin de encontrar aquellos títulos disponibles en formato digital, minimizando así el tiempo de digitalización

Paso 6: Recolección de los textos de las bibliotecas correspondientes y de las oficinas de los profesores

Paso 7: Proceso de fotocopiado de cada texto con el fin de construir una base de datos en papel, para consultas posteriores

Paso 8: Entrenamiento de un equipo de asistentes para escanear y compilar todos los textos

Paso 9: Procesamiento de todos los textos del corpus en formato plano (*txt) a través del etiquetador morfosintáctico El Grial y correspondiente carga en la plataforma en línea www.elgrial.cl

\subsubsection{Recolección del Corpus Profesional}

Con el fin de recopilar el corpus del ámbito profesional en las empresas y/o instituciones, procedimos a contactar a todos los ex alumnos de las cuatro carreras seleccionadas en el ámbito académico, considerando un período de cinco años (2000 al 2006). En este primer contacto buscábamos comprobar si los sujetos correspondían al perfil del egresado determinado por la carrera. Esto quiere decir que identificamos a aquellos sujetos que se desempeñan laboralmente dentro de los dominios que cada una de las cuatro carreras proyecta para su profesional egresado.

Vale la pena señalar que no buscamos identificar ni estudiar el soporte o medio en que se almacena o transmite el material del corpus profesional (papel, medio electrónico, Internet, etc.). Nuestro interés se focaliza en construir un panorama de los principales géneros que circulan en cada ámbito de especialidad en el medio laboral; por ello, esta parte del estudio no persigue un propósito cuantificador de cada género identificado, tal como sí era el propósito en el Corpus Académico. De este modo, el objetivo último de esta recolección es conocer las prácticas de comunicación escrita en cada ambiente laboral y recolectar la mayor cantidad posible de material escrito prototípico a que estos sujetos se exponen en el desempeño de sus funciones. Como 
se aprecia, el corpus profesional se diferencia del corpus académico en cuestiones de universalidad y representatividad.

En la Tabla 2 se sintetizan las acciones realizadas para la construcción del corpus profesional. Ellas se resumen en doce pasos.

Tabla 2

Formato empleado para la recolección y procesamiento Corpus Profesional

Doce pasos seguidos para recolectar el Corpus Profesional PUCV-2006

Paso 1: Construcción de una primera base de datos de los profesionales egresados de las cuatro carreras en estudio en un período de cinco años

Paso 2: Determinación de un número de profesionales en ejercicio que cumplan con el requisito de desempeñarse en el ámbito de su título profesional con el fin de solicitarles materiales escritos

Paso 3: Contacto telefónico con los sujetos de la muestra de egresados y programación de entrevista

Paso 4: Realización de entrevistas in situ con el apoyo de un protocolo ad hoc, con el objetivo de solicitar textos escritos ejemplares de uso cotidiano en el medio laboral

Paso 5: Contacto posterior por correo electrónico con los profesionales de la muestra con el fin de que proporcionen otros materiales en formato electrónico, comprometidos en la entrevista

Paso 6: Búsqueda en bibliotecas, empresas o en Internet de ciertos materiales mencionados, pero no entregados por los profesionales encuestados

Paso 7: Construcción de una segunda base de datos a partir de los alumnos en práctica profesional terminal de las cuatro carreras en estudio

Paso 8: Determinación de un número accesible de entrevistados por disciplina o área de especialización con el fin de contactarlos y solicitarles materiales de uso laboral

Paso 9: Contacto a través de teléfono, correo electrónico o de los profesores supervisores de prácticas profesionales para fijar entrevista en la universidad con el objetivo de solicitar textos escritos de uso cotidiano en el medio laboral

Paso 10: Proceso de fotocopiado de todos los textos recolectados del primer y segundo grupo con el fin de construir una base de datos en papel

Paso 11: Entrenamiento de un equipo de asistentes para escanear y compilar todos los textos

Paso 12: Procesamiento de todos los textos del corpus en formato plano (*txt) a través del etiquetador morfosintáctico El Grial y correspondiente carga en la plataforma en línea www.elgrial.cl

\subsubsection{El Corpus PUCV-2006: Las disciplinas}

Tal como se ha adelantado, el Corpus Académico PUCV-2006 se recolectó a través de cuatro disciplinas (dos de las CB\&I y dos de las CS\&H). Estas disciplinas serán indagadas 
tanto desde los entornos académicos universitarios como desde los contextos profesionales. En la Tabla 3 se detalla el desglose por área del conocimiento y por disciplina.

Tabla 3

Areas académicas y profesionales

\begin{tabular}{|l|l|}
\hline \multicolumn{2}{|c|}{ Areas Académicas y Profesionales } \\
\hline $\begin{array}{l}\text { Ambito de las Ciencias Básicas y de la Ingeniería } \\
\text { (CB\&I) }\end{array}$ & Ingeniería en Construcción (IC) \\
\cline { 2 - 2 } & Química Industrial (QUI) \\
\hline $\begin{array}{l}\text { Ambito de las Ciencias Sociales y Humanas } \\
(\mathrm{CS} \& \mathrm{H})\end{array}$ & Trabajo Social (TS) \\
\cline { 2 - 2 } & Psicología (PSI) \\
\hline
\end{tabular}

La elección de estas cuatro disciplinas científicas se basó en tres criterios:

- Necesidad de explorar disciplinas diferentes a las clásicamente indagadas en idioma inglés y en la mayoría de los trabajos disponibles en español, tales como leyes, medicina, economía, historia y negocios.

- Búsqueda de comparación y contrastación, desde diversas ópticas, de los géneros y las características prototípicas de los textos del medio de formación académica universitaria

- Búsqueda de comparación y contraste, en diversos puntos, entre disciplinas de CB\&I y de las CS\&H.

\section{Resultados}

En la primera parte de esta sección entregamos una descripción cuantitativa del corpus recolectado. Dada la naturaleza diferente del tipo de recolección entre el corpus académico y el profesional, revisaremos estas cifras separadamente y con grado diverso de profundidad.

\subsection{CORPUS ACADEMICO}

Para mejor visualización de la distribución del corpus por ámbito y por carrera, en la Gráfico 1 se presentan, en principio, las cifras en porcentajes.

Un primer análisis, basado en los datos del Grafico 1, nos conduce a inferir que, dada la cantidad de textos recolectados, existiría un mayor número de textos para los alumnos de las CS\&H, a diferencia de lo que ocurre en las CB\&I. En otras palabras, los alumnos de CS\&H podrían estar leyendo una cantidad mucho mayor de material escrito en comparación con los alumnos de las carreras de CB\&I. Con el fin de despejar estas inferencias, en la Tabla 1, se entregan cifras desplegadas en términos de número de textos, número de palabras por cada carrera en estudio y los respectivos porcentajes. 
Gráfico 1

Distribución por carrera Corpus Académico PUCV-2006

Corpus Académico PUCV-2006

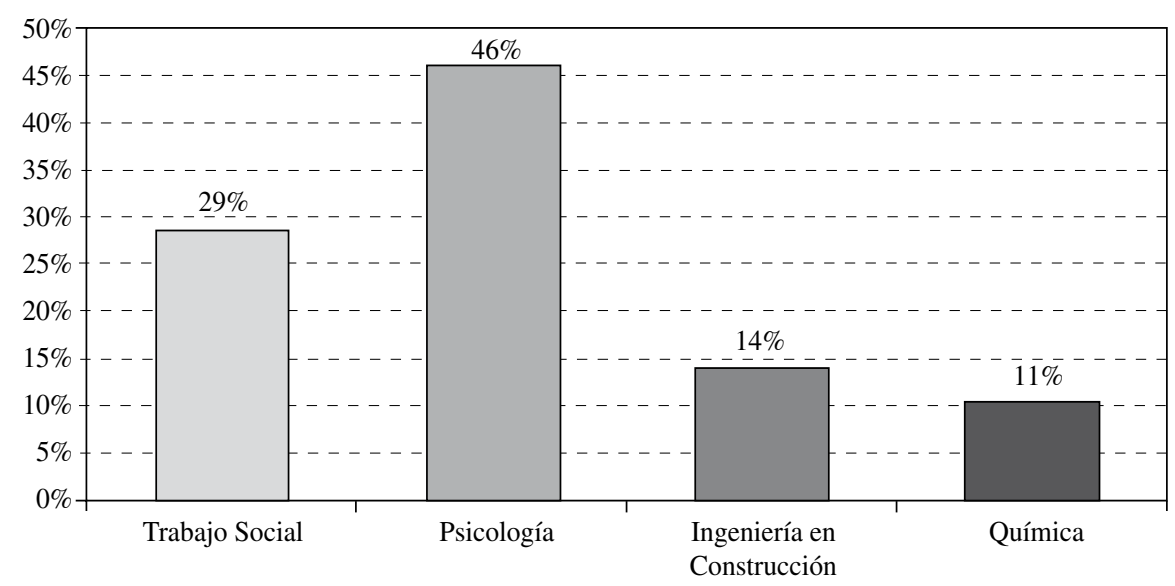

Tabla 4

Constitución Corpus Académico PUCV-2006 en formato digital

\begin{tabular}{|l|c|c|c|c|}
\cline { 2 - 5 } \multicolumn{1}{c|}{} & $\mathrm{N}^{\circ}$ Textos & $\%$ & $\mathrm{~N}^{\circ}$ Palabras & $\%$ \\
\hline Psicología (PSI) & 227 & 46 & 21.933 .860 & 37 \\
\hline Trabajo Social (TS) & 142 & 29 & 18.641 .309 & 32 \\
\hline $\begin{array}{l}\text { Ingeniería en } \\
\text { Construcción (IC) }\end{array}$ & 69 & 14 & 8.734 .086 & 15 \\
\hline Química Industrial (QUI) & 53 & 11 & 9.285 .375 & 16 \\
\hline TOTALES & 491 & $100 \%$ & 58.594 .630 & $100 \%$ \\
\hline
\end{tabular}

En un análisis preliminar, basado en los datos de la Tabla 4, se puede pensar que, dada la cantidad de textos recolectados, existe un mayor número de textos de lectura para los alumnos de las CS\&H, a diferencia de lo que ocurre en las CB\&I. En otras palabras, los alumnos de CS\&H se exponen a una cantidad mucho mayor de material escrito en comparación con los alumnos de las carreras de CB\&I. De acuerdo a estas cifras, se puede suponer, por ejemplo, que los alumnos de PSI leerían cuatro veces más que los alumnos de QUI.

Un análisis más profundo, basado ahora en el número de palabras por disciplina y los respectivos porcentajes confirma lo anteriormente dicho en cuanto a la distinción en cantidad de textos y extensión de ellos entre las CS\&H y las CB\&I. Esta distribución irregular revela una interesante concentración de mayor cantidad de material escrito disponible al acceso de los alumnos en formación en las disciplinas de las CS\&H, entre las que PSI destaca por el mayor porcentaje de ocurrencia de textos (227: 37\% 
del total) y el mayor número de palabras (21.933.860). En esta misma tabla se aprecia que, comparativamente, QUI ostenta el número más bajo de textos recolectados (53: $11 \%$ del total del corpus).

Estos datos preliminares construyen un primer panorama muy singular, pues no se cuenta con antecedentes similares producto de investigaciones de esta naturaleza en lengua española ni en otras lenguas. Las investigaciones disponibles suelen abordar un corpus intencionado de tamaño reducido o seleccionado aleatoriamente de uno o varios géneros académicos; en otros casos se trabaja más bien a modo de ejemplificaciones. Tampoco contamos con otros trabajos de corte naturalístico, en los cuales se recolecte el universo de materiales académicos en disciplinas en estas u otras áreas del conocimiento.

En el ámbito cuantitativo, las cifras presentadas en la Tabla 4 constituyen un verdadero hito. No tenemos antecedentes de un corpus académico escrito de estas características que alcance tal dimensión con un grado tan alto de representatividad y circunscripción temática. $\mathrm{O}$ sea, un corpus en el que exista una subdivisión por disciplinas y los textos estén agrupados en géneros discursivos; además de que estén disponibles en línea para acceso gratuito a consultas (www.elgrial.cl). Así, un corpus con cerca de 60 millones de palabras en formato digital, tematizado y tipologizado se constituye en una herramienta fundamental para el desarrollo de investigaciones de vanguardia desde los enfoques de la lingüística de corpus en lengua española. Con ello, el Corpus Académico PUCV-2006 se suma a los ya existentes en el sitio El Grial, de modo que el material digital disponible sobrepasa -en total- los 120 millones de palabras, posibilitándose consultas del tipo descrito por Parodi (2006a) y Venegas y Silva (2007).

Justamente con el objetivo de profundizar en el análisis del material escrito recolectado, procedimos a su estudio y clasificación en tipos de géneros. Para ello empleamos cinco criterios: a) macropropósitos comunicativos, b) modos de organización del discurso, c) relación entre los participantes, d) contexto ideal de circulación y e) modalidad. A continuación, en la Tabla 5, se nombran los nueve géneros identificados y se consignan las cifras brutas de ocurrencia a partir del total de textos del Corpus Académico PUCV-2006. Definiciones precisas de cada género se encuentran en Parodi, Venegas, Ibáñez y Gutiérrez (2008).

La organización de la información en la Tabla 5 ha seguido el principio del orden alfabético por los nombres otorgados a los géneros. Decidimos buscar nombres simples, cotidianos y de fácil acceso y transparencia en su uso. Como se aprecia, a partir de esta tabla emerge un panorama muy heterogéneo pero con claras concentraciones. En principio, se puede decir que son dos los géneros más recurrentes: Texto Disciplinar (TD) y Manual (MA). Ello entrega un panorama global inicial en que se conjuga, por una parte, el saber disciplinar propiamente tal a través del TD que aborda conocimiento especializado, a veces de alto grado de complejidad; por otra, encontramos el MA que, aunque está fuertemente orientado por el conocimiento disciplinar, cuenta con un carácter didáctico variable en que se busca, en la mayoría de los casos, difundir saberes con apoyo de diversos recursos educativos (gráficos, tablas, diagramas, etc.) y llevar a los lectores al desarrollo de ejercicios y aplicación de conocimientos. No deja de llamar la atención que un corpus de estas características presente, comparativamente, escasa ocurrencia de, por ejemplo, la Guía Didáctica (GD). Aunque ellas ocupan el tercer lugar en jerarquía numérica, estimamos que su cantidad es limitada, 
dado que se ha recolectado el material de cuatro carreras universitarias y a partir de currículos académicos con cuatro a cinco años de duración.

Tabla 5

Distribución del Corpus Académico por géneros

\begin{tabular}{|l|c|}
\hline \multicolumn{1}{|c|}{ Géneros } & Número de Textos \\
\hline Artículo Investigación Científica (AIC) & 22 \\
\hline Conferencia (CONF) & 2 \\
\hline Diccionario (DIC) & 41 \\
\hline Guía Didáctica (GD) & 11 \\
\hline Informe (INF) & $126(*)$ \\
\hline Manual (MA) & 15 \\
\hline Norma (NM) & 3 \\
\hline Test (TEST) & $270(*)$ \\
\hline Texto Disciplinar (TD) & 491 \\
\hline TOTAL & \\
\hline
\end{tabular}

También resulta interesante constatar la escasa aparición del Artículo de Investigación Científica (AIC). Podría pensarse que este medio de transmisión de conocimiento especializado ocuparía un lugar y espacio más relevante, al menos dentro de las carreras de CB\&I. La ocurrencia de solo 22 AIC en el total del corpus resulta limitada, si se piensa que este es un medio vigente de información actualizada y de vanguardia.

A continuación se presenta la Figura 3 que de modo gráfico da cuenta de la distribución de los géneros académicos a través de las disciplinas.

No sorprende comprobar empíricamente que el Manual (MA) es el género académico por excelencia y el único que circula en las cuatro disciplinas en indagación. El MA, independientemente del área disciplinar, cumple un claro propósito pedagógico en el ámbito universitario. Su estructura retórica prototípica, articulada en presentación de conceptos, planteamiento de problemas y ejercicios, resolución de los mismos, ampliación de ejercitación e inclusión de glosarios terminológicos (Parodi, 2008b), revela la entrega de núcleos de conocimiento codificados de manera sucinta y que, al mismo tiempo, despliega recursos instruccionales precisos para andamiar el acceso a la información nueva y ponerla a prueba a través de problemas y preguntas directivas. Asuntos todos resueltos paso a paso a través de los cuales se demuestra el modo de operar y actuar en el marco disciplinar. Esta articulación gradual de acercamiento a los núcleos temáticos, apoyados permanentemente con ejercitación y resolución pautada, implica una planificada interacción entre escritor y lector, en donde el rol del aprendiz queda clara y definitivamente especificado. Así, el autor-escritor actúa como el especialista disciplinar que guía al estudiante no iniciado en su aproximación 
a un nuevo conocimiento especializado por medio de pasos organizados jerárquica y progresivamente. Esta interacción escritor-lector resulta definitivamente transparente en el mecanismo de diseminación de información. Se opera así desde un eje altamente especializado (el escritor-autor) hacia una audiencia lega o semilega en un contexto educativo particular.

Figura 3

Distribución de géneros académicos por disciplina

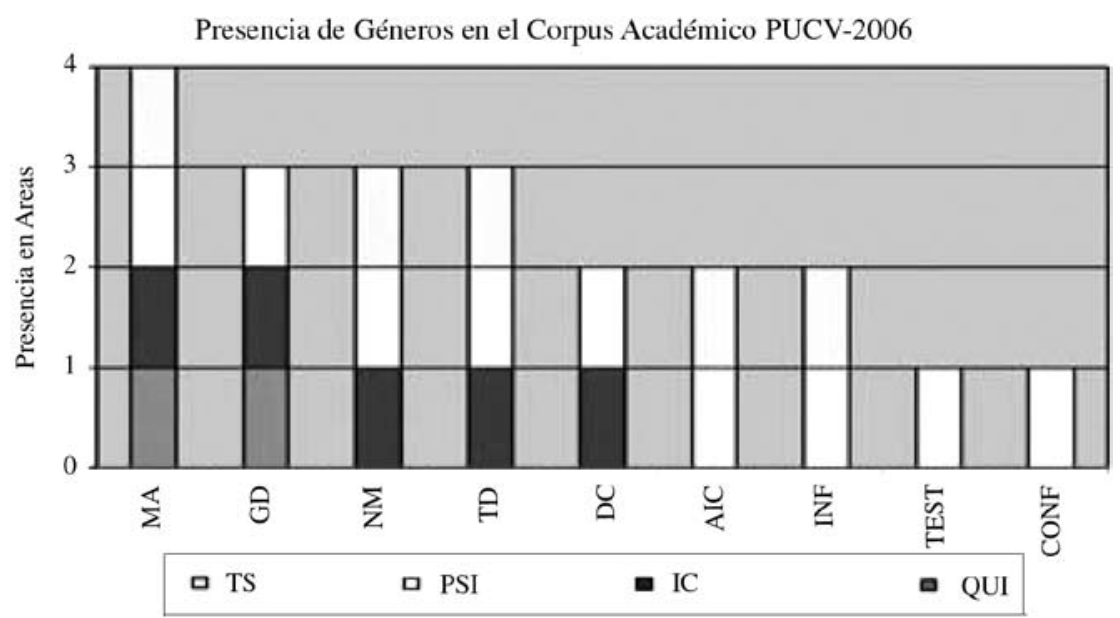

\subsection{CORPUS PROFESIONAL}

A continuación entregamos una breve descripción cuantitativa del Corpus Profesional. Vale la pena recordar que no se perseguía una búsqueda exhaustiva de todos los textos en circulación, sino más bien construir un panorama de la diversidad de géneros. Esto quiere decir que el acento estuvo en recolectar la mayor cantidad posible de muestras de géneros, aunque también se cuantificó el material obtenido durante el tiempo de búsqueda.

Tabla 6

Constitución del Corpus Profesional

\begin{tabular}{|l|c|c|}
\hline \multicolumn{1}{|c|}{ Area } & $\mathrm{N}^{\mathrm{o}}$ Textos & $\%$ \\
\hline Psicología (PSI) & 220 & 50 \\
\hline Trabajo Social (TS) & 101 & 23 \\
\hline Ingeniería Construcción (IC) & 62 & 14 \\
\hline Química Industrial (QUI) & 59 & 13 \\
\hline Total & 442 & 100 \\
\hline
\end{tabular}


Interesantemente, los datos de la Tabla 6 revelan cierta similitud con la proporcionalidad de las cifras del Corpus Académico, entregadas en el Gráfico 1. Así, aunque no exactamente bajo los mismos procedimientos de recolección, la mayor existencia de material disponible se reitera en las áreas de CS\&H, siendo PSI el área que lidera el grupo. No deja de llamar la atención la decreciente distribución porcentual ocurrida en los mismos términos que en el Corpus Académico: PSI, TS, IC y QUI. Sin lugar a dudas, esto no es producto del azar; debe indicar una tendencia reveladora respecto a la cantidad de textos escritos que circula en la universidad y en el medio laboral en ámbitos disciplinares diversos. Ciertamente también representa implicancias acerca de las posibles prácticas divergentes de lectura y escritura entre disciplinas de las CS\&H y de las CB\&I.

Siguiendo los mismos procedimientos de clasificación empleados para el Corpus Académico, todos los textos de Corpus Profesional fueron analizados por el equipo de investigación. Se llegó así a determinar la existencia de veintiocho (28) géneros discursivos en las cuatro áreas disciplinares en indagación. Tal como se apuntó en el caso del corpus académico, definiciones precisas de cada género profesional se encuentran en Parodi, Venegas, Ibáñez y Gutiérrez (2008). En la Tabla 7 se consigna en orden alfabético el listado de géneros y de su correspondiente abreviatura.

Listado de los 28 géneros del Corpus Profesional

\begin{tabular}{|l|l|}
\hline 1. Artículo de Investigación Científica (AIC) & 15. Manual de Operación (MAOP) \\
\hline 2. Base Licitación (BL) & 16. Memorando (ME) \\
\hline 3. Catálogo Comercial (CC) & 17. Memoria de Cálculo (MEM.CAL) \\
\hline 4. Certificado (CERT) & 18. Noticia (NOT) \\
\hline 5. Conferencia (CONF) & 19. Norma (NM) \\
\hline 6. Convocatoria (CONV) & 20. Orden Médica (OM) \\
\hline 7. Cotización (COTZ) & 21. Pauta de Observación (PO) \\
\hline 8. Declaración (DEC) & 22. Plan de Desarrollo (PD) \\
\hline 9. Diccionario (DC) & 23. Plano (PLA) \\
\hline 10. Ficha Médica (FM) & 24. Proyecto de Investigación (PI) \\
\hline 11. Folleto (FOLL) & 25. Registro (REG) \\
\hline 12. Informe (INF) & 26. Tesis (TES) \\
\hline 13. Ley (LEY) & 27. Test (TEST) \\
\hline 14. Manual (MA) & 28. Texto Disciplinar (TD) \\
\hline
\end{tabular}

La diversidad de géneros que emergen desde el campo laboral se revela mucho más rica y heterogénea que la que se detecta en el ámbito universitario. En términos numéricos, es exactamente cuatro veces más grande. Se observa gran especialización y restricción disciplinar en algunos de ellos (Manual de Operaciones, Memoria de 
Cálculo, Plan de Desarrollo, Proyecto de Investigación), así como un posible mayor grado de uso general y amplia circulación en otros (Conferencia, Orden Médica, Diccionario, Plano, Noticia). A primera vista, se nota que algunos géneros son los mismos identificados en el Corpus Académico (Artículo de Investigación Científica, Norma, Manual, etc.). Volveremos sobre este punto en detalle más adelante.

Con el fin de mostrar la ocurrencia de cada género a través de las cuatro disciplinas, estos se organizaron gráficamente en la Figura 4.

Figura 4

Distribución de géneros profesionales por disciplina

Presencia de Géneros en el Corpus Profesional PUCV-2006

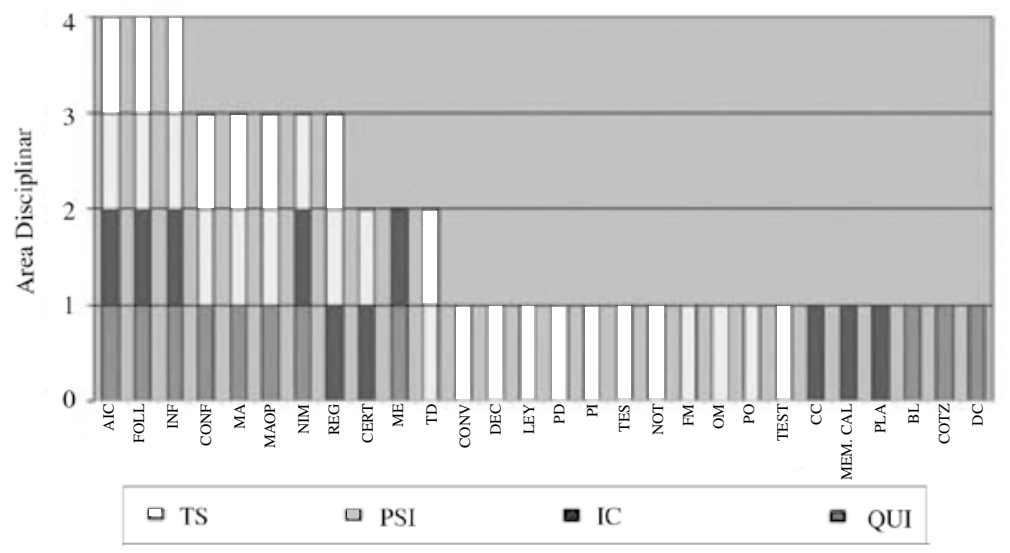

En primer lugar, se debe consignar que solo tres géneros (Artículo de Investigación Científica (AIC), Folleto (FOLL) e Informe (INF)) circulan transversalmente en las cuatro disciplinas. Este hallazgo resulta muy revelador pues prueba empíricamente lo sostenido teóricamente más arriba en cuanto a la transversalidad disciplinar de ciertos géneros. No resulta altamente extraño que el AIC aparezca en las cuatro disciplinas, ya que constituye una fuente actualizada de información, así como instrumento vital de adquisición de conocimiento de punta. Ello implica que los cuatro profesionales utilizan este medio escrito para acceder a información de su disciplina dentro de sus actividades laborales cotidianas. El Folleto y el Informe son también instrumentos importantes en los procesos de entrega y recepción de información. El Folleto aporta datos relevantes y los hace circular entre audiencias diversas (Por ejemplo, un folleto médico acerca de enfermedades contagiosas). Por su parte, el Informe deja constancia, entre otros, de una situación, procedimiento o análisis de un caso. En segundo lugar, los datos de la Figura 4 muestran que existen sólo tres géneros (Conferencia, Manual y Manual de Operaciones) ligados a tres disciplinas (TS, PSI y QUI), mientras que la Norma es exclusiva de PSI, IC y QUI. Por su parte, el Reglamento es prototípico de TS, PSI e IC. En tercer lugar, tres géneros se encuentran en solo dos disciplinas: el Certificado en PSI e IC, el Memorando en IC y QUI y, por último, el Texto Disciplinar en TS y PSI. Es interesante comprobar que algunos géneros como el Certificado circulan en disciplinas tanto de CS\&H como en CB\&I, mientras que los otros dos restantes se 
registran muy ligados al ámbito de especialidad. El MA ocurre en las llamadas ciencias duras y el Texto Disciplinar vuelve a mostrar, al igual que en el Corpus Académico, su importancia en el ámbito de las Ciencias Sociales y Humanas. Esta distinción se revela con cierta consistencia y tiende a apuntar a un modo divergente de transmisión y construcción de conocimientos disciplinares.

Por último, se registra que de los veintiocho géneros, sólo once transitan a través de cuatro, tres o dos disciplinas. Los restantes dieciséis son exclusivos de una sola de las cuatro disciplinas en estudio. Ello quiere decir que el $61 \%$ de los géneros son prototípicos de un solo dominio de especialidad, mostrando la especificidad de la comunicación disciplinar y los requerimientos de construcción de instrumentos discursivos particulares para servir a propósitos determinados. En esta línea de análisis porcentual, cabe destacar que el restante $39 \%$ de los géneros indica algún grado variable de distribución a través de las disciplinas y que solo el 10\% de ellos aparece en las cuatro.

\subsection{GENEROS ACADEMICOS Y PROFESIONALES: PUNTOS DE ENCUENTRO}

En la parte final de este artículo enfocamos uno de los núcleos del mismo, ya consignado en su título, cual es la comparación entre los hallazgos en ambos corpus: académico y profesional. La Figura 5 da cuenta de la interesante situación que se produce al determinar áreas de independencia y áreas compartidas, independientemente de la disciplina de la que provengan. Es importante dejar en claro que este esquema captura las intersecciones entre los géneros sin tomar en cuenta la adscripción disciplinar. Esto quiere decir que la presencia de un género en un corpus no implica que ese género haya sido detectado en todas las disciplinas involucradas en ese corpus.

Figura 5

Especificidades y encuentros de géneros entre el CA y el CP (independientemente de las disciplinas)

Presencia de Géneros en el Corpus Académico y el Corpus Profesional PUCV-2006

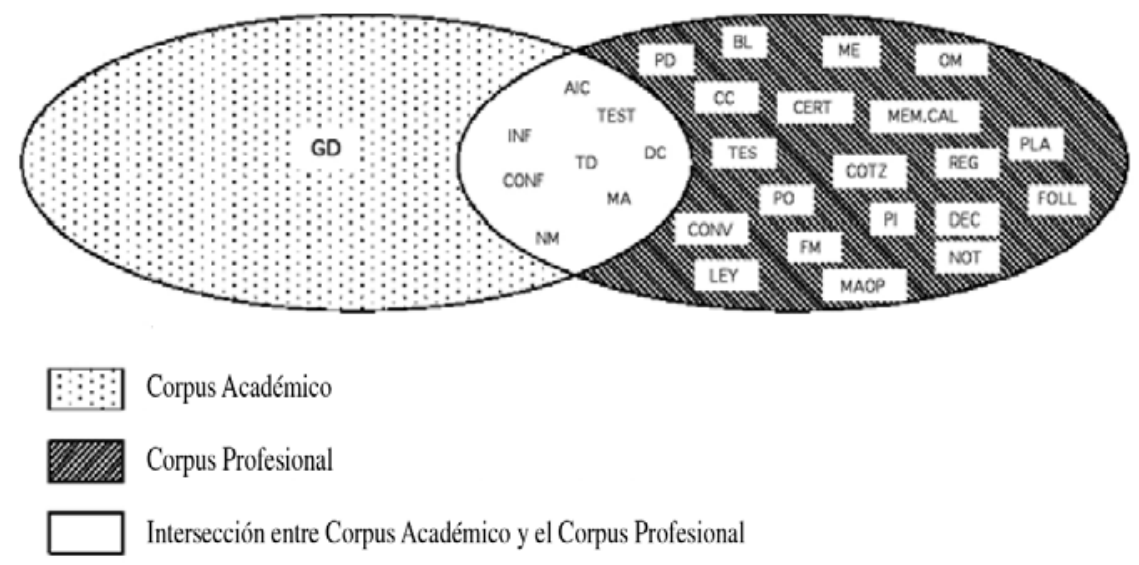


Solo un género emerge como exclusivo en el Corpus Académico, la Guía Didáctica (GD), mientras que veinte de ellos resultan exclusivos del Corpus Profesional. Ocho géneros se revelan como compartidos y, por ende, transitan paralelamente por los ámbitos académicos y profesionales. Estos hallazgos son altamente reveladores de una situación no previamente identificada en la literatura especializada. Al menos en las cuatro disciplinas indagadas a partir de una institución de educación superior (PUCV), son escasos los géneros que se pueden declarar como prototípicamente académicos, pues un alto porcentaje de ellos circula también y/o exclusivamente en el ámbito profesional. Como se ha dicho, la GD es el único género con exclusividad de la educación superior en estas cuatro carreras universitarias, su carácter pedagógico y decididamente didáctico educativo justifica tal aparición.

Los ocho géneros compartidos con el mundo laboral constituyen un puente entre la academia y la vida profesional. De hecho, entre otros, el Manual (MA), el Artículo de Investigación Científica (AIC) y el Texto Disciplinar (TD) son parte de estos géneros que aportan un propósito y un contenido especializado en la formación universitaria y que se consideran como repositorios de conocimientos disciplinares. Interesantemente, como se aprecia, estos tres géneros cumplen muy posiblemente funciones muy similares en el mundo profesional, aunque los propósitos de su utilización pueden variar grandemente.

Es posible pensar que el diseño emergente a partir de la Figura 5 constituya un adecuado continuum en la gradación del acceso e incorporación a la comunidad discursiva, aunque de hecho difícilmente responda a una cuidadosa planificación consciente. Esto quiere decir que se procede - desde un punto de inicio- situado en la academia a partir de un género muy didáctico y divulgativo (GD), junto a otros ocho que tienen un carácter más especializado y que también serán encontrados por el sujeto aprehendiente, con posterioridad, en su vida profesional. El punto extremo del continuum, según lo muestra la Figura 5, será el de mayor heterogeneidad y amplitud de géneros y se revelará al sujeto profesional ya en su medio laboral.

Por otra parte, también es factible argumentar desde el lado contrario. La reducida variedad de géneros encontrados en el medio académico (solo 9) en contraste con la mayor amplitud y diversidad del medio profesional podría ser un escollo en el adecuado transitar desde la academia al medio laboral, pues los accesos al saber y al hacer (es decir, los géneros discursivos, en este caso escritos), serían muy diferentes a los conocidos y manejados durante los cinco años de formación universitaria. En este sentido, los hechos descritos podrían ciertamente constituirse en una lentificación del proceso de integración y que afectaría al desempeño inicial del sujeto ya graduado de la universidad. Esta diversificación de géneros entre la academia y el mundo profesional impone nuevos mecanismos discursivos de acceso al conocimiento y a la práctica de la actividad profesional, mucha de ella ejecutada a través de medios lingüísticos escritos. En este punto cabe preguntarse: ¿debe la academia hacerse cargo de la formación universitaria de los géneros que son exclusivos del medio profesional?, ¿debe la academia tomar conocimiento y conciencia y, por ende, acciones educativas respecto de estos géneros profesionales? o ¿deben quedar los profesionales enfrentados sin mediar procesos de alfabetización especializada de ningún tipo a los nuevos mecanismos discursivos que su vida laboral les impone? Sin lugar a dudas estas preguntas trascienden los límites de este trabajo y corresponden a interrogantes que deberán ser estudiadas en conjunto con las unidades educativas especializadas. 
Solo diremos que la alfabetización especializada de los discursos disciplinares no es una cuestión que solo deba acontecer (como de hecho se hace) en las universidades, también es responsabilidad de las empresas e instituciones tomar conocimiento de estos hechos y decidir rumbos de acciones.

Un dato importante que la comparación entre ambos corpus revela es el hecho de que la Guía Didáctica (GD) es el único género prototípico del Corpus Académico. Este hallazgo podría no sorprender, pero su constatación empírica muestra así que la academia universitaria emplea escasos recursos discursivos prototípicos para la realización de ejercitación de los contenidos en enseñanza. También se hace evidente que por este medio se abren espacios discursivos que permiten poner en práctica núcleos teóricos o aplicados de modo muy pedagógico.

El panorama de conjunto que hemos venido construyendo permite efectuar un dimensionamiento del corpus en estudio, así como - por ejemplo- de vinculaciones entre las disciplinas y la variedad de géneros identificados. A partir de ello, se detecta una clara tendencia hacia una reducción o incremento progresivo en términos cuantitativos a partir de la carrera, del número de textos, del número de palabras totales, de la adscripción disciplinar y de la variedad existente de géneros tanto académicos como profesionales. La Figura 6, por medio de un diseño de pirámide invertida, deja en evidencia estas regularidades.

Figura 6

Dimensionamiento de ciertas variables del corpus

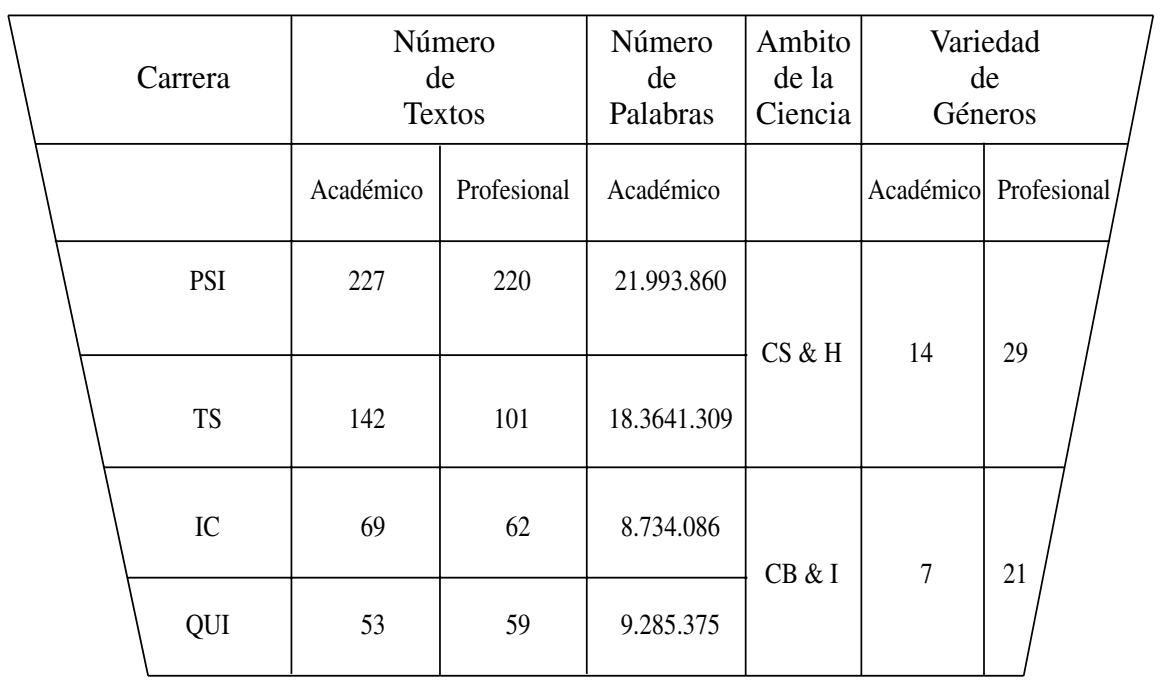

Tal como se constata, existe un cierto patrón regular emergente a partir de las variables del corpus. Esta progresiva distribución cuantitativa asociada a disciplinas, áreas del conocimiento y géneros ofrece un hallazgo que deberá ser profundizado y cuya tendencia deberá ser corroborada desde otros corpus y en otras instituciones de educación superior. También desde estos datos se podrían, eventualmente, establecer proyecciones hacia nuevas investigaciones y generar nuevas hipótesis. 
Entre otras cuestiones, los datos revisados hasta aquí permiten señalar que la alfabetización académica y profesional se vuelve un requisito necesario para el desarrollo de lectores y escritores eficientes, dado que se registra un alto número de géneros emergentes en los contextos profesionales, diferentes a los empleados en la vida académica universitaria. En este contexto, las competencias discursivas escritas deben ser debidamente andamiadas para que el uso efectivo de los géneros y el cumplimiento de las funciones para las cuales han sido creados logren aportar a una comunicación de calidad.

\section{Conclusiones}

Con el propósito de abordar secuencialmente los hallazgos más relevantes y aportar algunas conclusiones, procedemos en virtud de tres focos: Corpus Académico, Corpus Profesional y puntos de acercamiento o distanciamiento entre ambos.

\subsection{EN CUANTO AL CORPUS ACADEMICO}

4.1.1. En cifras numéricas, se registran diferencias importantes tanto en número de textos como en número de palabras entre las CS\&H y las CB\&I, lo que dice relación tanto con la cantidad diferencial de material escrito al que estarían expuestos los alumnos en formación disciplinar en una y otra área, como a la mayor variedad de géneros que circulan en unas y otras carreras universitarias. Las implicancias para la construcción de conocimiento disciplinar, la variedad de géneros discursivos y el desarrollo de habilidades de comprensión de textos escritos son múltiples y se abren como caminos para indagar.

4.1.2. Dos géneros son los de mayor ocurrencia en este corpus: el Texto Disciplinar (270 textos) y el Manual (126 textos). Este hecho pone de manifiesto, por un lado, el carácter altamente disciplinar de la instrucción universitaria con textos especializados con escasa o nula atención a la audiencia lega o semilega y, por otro, muestra la preocupación por andamiar los aprendizajes a través de textos que aportan recursos didácticos y pedagógicos para entregar paulatina y metodológicamente los contenidos.

4.1.3. Existe mayor variedad de géneros en Ciencias Sociales y Humanas (5 en TS y 9 en PSI) que en Ciencias Básicas y de la Ingeniería (2 en QUI y 5 en IC). Dentro de ellos, queda claro que es PSI el área que revela la mayor heterogeneidad de géneros académicos, pues cuenta con presencia de todos los identificados en este corpus. Posteriores investigaciones deben enfocarse en el estudio detallado y contrastivo de estos géneros en uno y otros ámbitos disciplinares con el fin de detectar similitudes y diferencias relevantes. Parte de nuestro equipo de investigadores ya se ha adentrado en estos asuntos (Parodi, 2008b, Ibáñez, 2008).

4.1.4. La identificación y distribución de estos nueve géneros a través de las cuatro disciplinas indica una interesante transversalidad de ciertos géneros académicos así como una menor tendencia a la exclusividad de recursos discursivos para una sola disciplina. El 78\% de estos nueve géneros está presente en al menos dos de las cuatro 
disciplinas en estudio (IC y TS), las cuales corresponden una a cada área del conocimiento. Así, solo el 22\% restante de estos géneros aparece marcado con exclusividad disciplinar y son todos ellos de PSI (TEST y CONF).

\subsection{EN CUANTO AL CORPUS PROFESIONAL}

4.2.1. Existe una mayor diversidad de géneros que los detectados en el Corpus Académico. Los veintiocho géneros identificados revelan interesantes medios de comunicación escrita muy prototípicos de las áreas disciplinares. Algunos de ellos con gran especialización en contextos y funciones específicas (entre otros: Memoria de Cálculo, Base de Licitación, Ficha Médica, Pauta de Observación).

4.2.2. De estos veintiocho géneros, solo once se comparten entre algunas o todas las áreas disciplinares. De modo que el $61 \%$ del total corresponde a una sola disciplina. Ello revela que la especialización en géneros más arriba indicada dice directa relación con un área particular del conocimiento.

4.2.3. La no ocurrencia de la mayoría de estos géneros en el Corpus Académico implica que los profesionales deben conocerlos y aprenderlos directamente en el ambiente laboral, sin mediar instrucción específica ni conocimientos previos de las organizaciones del género. Se hace imperativo explorar en detalle estos géneros y realizar análisis más detallados que brinden mayores pistas acerca de sus rasgos prototípicos, de su modo de organización discursiva, de su estructura retórica, etc.

\subsection{EN CUANTO A AMBOS CORPUS}

4.3.1. En total, restados los coincidentes, se detectan veintinueve géneros diversos entre el Corpus Académico y el Corpus Profesional en las cuatro áreas disciplinares.

4.3.2. No existe ningún género discursivo que coexista tanto en el corpus Académico como en el Corpus Profesional con presencia en las cuatro disciplinas. Ello pone de manifiesto la especificidad genérica de las disciplinas en el ámbito universitario y en el laboral. Esto quiere decir que no se dispone de un medio que atraviese desde el medio académico al medio profesional en las cuatro disciplinas en estudio a modo de pasaje discursivo prototípico. Cada área revela características genéricas idiosincrásicas.

4.3.3. Solo la Guía Didáctica emerge como el único género que distingue al Corpus Académico del Profesional a través de las cuatro disciplinas. Interesantemente, la GD es un género caracterizado por especial énfasis en recursos didácticos y tareas instruccionales, hechos prototípicos del ámbito educativo.

4.3.4. Son escasos los puntos de intersección entre ambos corpus a partir de géneros que coincidan en las cuatro disciplinas. Solo siete géneros se entrecruzan. De estos siete géneros, un total de cinco de ellos, vale decir, el $71 \%$, se presenta exclusivamente en el ámbito académico y profesional en el área de las Ciencias Sociales y Humanas. 
4.3.5. Los hallazgos aportados permiten señalar que existen diferencias importantes que emergen entre el Corpus Académico y el Corpus Profesional en lo que respecta a los géneros discursivos. Comparativamente hablando, los datos provenientes del Corpus Profesional marcan las diferencias con el Corpus Académico: mayor heterogeneidad de géneros ( 28 y 9 respectivamente) y mayor especialización y foco a través del empleo de géneros prototípicos asociados a disciplinas (61\% de géneros profesionales en un solo dominio disciplinar versus $22 \%$ en el caso de los géneros académicos).

4.3.6. Por último, vale la pena continuar preguntándose: ¿Se comunica la ciencia del mismo modo en disciplinas diversas?, ¿existen pasajes discursivos desde el ámbito universitario al profesional?, ¿es posible pensar en una jerarquización de los géneros académicos como caminos orientadores en la formación universitaria?

4.3.7. Algunas respuestas se han avanzado en esta investigación, aunque es evidente que todas estas preguntas deben ser revisitadas desde nuevas áreas disciplinares y con corpus más amplio y diverso. Sin lugar a dudas, el concepto de género merece continuar en el punto de mira para hacerlo cada vez más preciso y operacionalizable.

\section{OBRAS CITADAS}

Alcaraz Varó, E., Mateo, J. y Yus, R., Eds. 2007. Las lenguas profesionales y académicas. Barcelona: Ariel.

Arnoux, E., Nogueira, S. y Silvestre, A. 2006. "Comprensión macroestructural y reformulación resuntiva de textos teóricos en estudiantes de institutos de formación de docentes primarios". Revista Signos 39 60:9-30.

Bazerman, Ch., Ed. 2008. Handbook of research on writing. History, society, school, individual, text. New York: Erlbaum.

- 1994. "Systems of genres and the enhancement of social intentions". Ed. A. Freedman y P. Medway. Genre and New Rhetoric. London: Taylor and Francis.79-101.

Bhatia, V. 2004. World of written discourse: a genre-based view. London: Continnum.

- 1993. Analysing genre: Language use in professional settings. London: Longman.

Biber, D., Connor, U. y Upton, T. 2007. Discourse on the Move. Amsterdam: Benjamins.

Bruce, I. 2008. Academic writing and genre. A systematic Analysis. Londres: Continuum.

Candlin, C., Ed. 2002. Research and Practice in Professional Discourse. Hong Kong: City University of Hong Kong Press.

Carlino, P. 2005. "Representaciones sobre la escritura y formas de enseñarla en universidades de América del Norte". Revista de Educación, 336 enero-abril: 143-168.

Castel, V., Aruani, M. y Severino, V., Eds. 2004. Investigaciones en ciencias humanas y sociales: Del ABC disciplinar a la reflexión metodológica. Mendoza: Editorial de la Facultad de Filosofía y Letras de la Universidad Nacional de Cuyo.

Castelló, M. Coord. 2007. Escribir y comunicarse en contextos científicos y académicos: Conocimientos y estrategias. Barcelona: GRAO.

Charaudeau, P. 2004. "La problemática de los géneros. De la situación a la construcción textual”. Revista Signos 37 56: 23-39.

Ciapuscio, G. 2007. "Epistemic modality and academic orality: Pilot study for COTECA Corpus Textual del Español Científico de la Argentina”. Ed G. Parodi, Working with Spanish Corpora. London: Continuum. 90-105.

—. 2003. Textos especializados y terminología. Barcelona: IULA. 
Connor, U. y Upton, T., Eds. 2004. Discourse in the Professions: Perspectives from corpus linguistics. Amsterdam: John Benjamins.

Cubo de Severino, L. Comp. 2005. Los textos de la ciencia. Buenos Aires: Comunicarte.

Curado, A., Edwards, P. y Rico, M. 2007. Approaches to Specialised Discourse in Higher Education and Professional Contexts. UK: Cambridge Scholars Publishing.

Devitt, A. 2004. Writing Genres. Carbondale: Southern Illinois University Press.

Facchinetti, R., Ed. 2007. Corpus Linguistics 25 Years on. Amsterdam: Rodopi.

Flowerdew, J., Ed. 2002. Academic discourse. London: Longman.

Freedman, A. y Medway, P., Eds. 1994. Genre and the New Rhetoric. London: Taylor \& Francis.

Gallardo, S. 2005. Los médicos recomiendan: Un estudio de las notas periodísticas sobre salud. Buenos Aires: Eudeba.

Halliday, M. 1978. Language as social semiotics. London: Arnold.

Halliday, M. y Hasan, R. 1989. Language, Context and Text Aspects of Language in a Social - Semiotic Perspective. Hong Kong: Oxford.

Harvey, A. Comp. 2005. En torno al discurso: Contribuciones de América Latina. Santiago de Chile: Ediciones Universidad Católica de Chile.

Heinemann, W. 2000. "Textsorten. Zur Diskussion um Basisklassen des Kommunizierens. Rückschau uns Ausblick”. Ed Adamzik, K., Textsorten. Tübingen: Stauffenburg Verlag Brigitte Narr GmbH. 9-29.

Heinemann, W. y Viehweger, D. 1991. Textlinguistik: eine Einfübrung. Tübingen: Niemeyer.

Hyland, K. 2000. "Disciplinary discourses: Writer stance in research articles". Eds. C. Candlin y K. Hyland, Writing texts, processes and practice. London: Longman. 99-121.

- 1998. Hedging in scientific research articles. Philadelphia: Benjamins.

Ibáñez, R. 2008. "El Texto Disciplinar y el acceso al conocimiento desde el análisis del género: ¿Regulación del conocimiento o persuasión?”. Ed. G. Parodi, Géneros Académicos y Géneros Profesionales: Accesos discursivos para saber y hacer. Valparaíso: Ediciones Universitarias de Valparaíso. 219-246.

—. 2007. "Cognición y comprensión: Perspectivas para un análisis crítico al trabajo investigativo de Rolf Zwaan". Revista Signos 40 63: 81-100.

Kress, G. y Threadgold, T. 1988. "Towards a Social Theory of Genre. Southern Review”, 21 3: 215-243.

Mahlberg, M. y Teubert, W., Eds. 2007. Text, discourse and corpora. Theory and Analysis. Londres: Continuum.

Marinkovich, J. 2001-2003. "La competencia textual narrativa en adolescentes chilenos y españoles". Lenguas Modernas 28-29: 145-163.

Martin, J. 1992. English text. System and structure. Philadelphia: Benjamins.

Martin, J. y Rose, D. 2008. Genre Relations: Mapping Culture. London: Equinox.

Montolío, E. Coord. 2002. Manual práctico de escritura académica, 3 vols. Barcelona: Ariel.

Núñez, P., Muñoz, A. y Mihovilovic, E. 2006. "Las funciones de los marcadores de reformulación en el discurso académico en formación”. Revista Signos, 39 62, 471-492.

Oteíza, T. 2006. El discurso pedagógico de la historia: Un análisis lingüístico sobre la construcción ideológica de la historia de Chile 1970-2001. Santiago de Chile: Frasis.

Parodi, G. 2008a. “¿Qué es ser lingüista en el siglo XXI?: Reflexión teórica y metateórica. Discurso de Incorporación a la Academia Chilena de la Lengua, como Miembro Correspondiente por Valparaíso”. Revista Signos 41 67:135-154.

—. 2008b. "La organización retórica del género Manual: ¿Una colonia encadenada?” Ed. G. Parodi, Géneros Académicos y Géneros Profesionales: Accesos discursivos para saber y hacer. Valparaíso: Ediciones Universitarias de Valparaíso. 169-198. 
2008c. "Lingüística de Corpus: Una introducción al ámbito". Revista de Lingüística Teórica y Aplicada, 451:93-119.

Parodi, G., Ed. 2007a. Lingüística de Corpus y Discursos Especializados: Puntos de Mira. Valparaíso: Ediciones Universitarias de Valparaíso.

—. Ed. 2007b. Working with Spanish Corpora. London: Continuum.

Ed. 2005. Discurso Especializado e Instituciones Formadoras. Valparaíso: Ediciones Universitarias de Valparaíso.

2004. "Textos de especialidad y comunidades discursivas técnico-profesionales: una aproximación basada en corpus computarizado". Estudios Filológicos 39:7-36.

- 2003. Relaciones entre lectura y escritura: una perspectiva cognitiva discursiva. Valparaíso: Ediciones Universitarias de Valparaíso.

Parodi, G., Venegas, R., Ibáñez, R. y Gutiérrez, R. M. 2008. "Géneros del discurso en el Corpus PUCV-2006: Criterios, definiciones y ejemplos”. Ed. G. Parodi, Géneros Académicos y Géneros Profesionales: Accesos discursivos para saber y hacer. Valparaíso: Ediciones Universitarias de Valparaíso, 39-74.

Peronard, M. 2007. "La Escuela Lingüística de Valparaíso: algunos principios fundantes". Revista Signos, 40 65: 489-494.

Peronard. M. y Gómez Macker, L. 1985. "Reflexiones acerca de la comprensión lingüística: Hacia un modelo". Revista de Lingüística Teórica y Aplicada 23:19-32.

Swales, J. 2004. Research Genres: Exploration and Applications. Cambridge: Cambridge University Press.

1998. Other Floors, Other Voices: A Textography of a Small University Building. Mahwah: Erlbaum.

1990. Genre analysis. English in academic and research settings. Cambridge: Cambridge University Press.

Torner, S y Battaner, P., Eds. 2005. Corpus PAAU 1992: Estudios descriptivos, textos y vocabulario. Barcelona: IULA.

Trosborg, A., Ed. 2000. Analysing Professional Genres. Amsterdam: Benjamins.

van Dijk, T. 2008. Discourse and context. A sociocognitive approach. Cambridge: Cambridge University Press.

—. 2006. "Discourse, context and cognition". Discourse Studies 81:159-177.

—. 2002. "Tipos de conocimiento en el procesamiento del discurso". Ed. G. Parodi, Lingüística e interdisciplinariedad: Desafíos del nuevo milenio. Ensayos en Honor a Marianne Peronard. Valparaíso: Ediciones Universitarias de Valparaíso. 43-66.

—. 1999. "Context models in discourse processing". Eds. H. van Oostendorp y S. Goldman, The construction of mental representations during reading. Mahwah, NJ: Erlbaum. 123-148.

_ 1997. "Cognitive context models and discourse". Ed. M. Stamenow, Language Structure, Discourse and the Access to Consciousness. Amsterdam: Benjamins. 189-226.

van Dijk, T. y Kintsch, W. 1983. Strategies of discourse comprehension. New York: Academic Press.

Venegas, R. 2006. "La similitud léxico-semántica en artículos de investigación científica en español: Una aproximación desde el Análisis Semántico Latente". Revista Signos 39 60: 75-106.

Vine, B. 2004. Getting things Done at Work. Amsterdam: Benjamins.

Virtanen, T., Ed. 2004. Approaches to cognition through text and discourse. Berlin: Mouton de Gruyter.

Wignell, P. 2007. On the discourse of social science. Darwin: Charles Darwin University Press. 